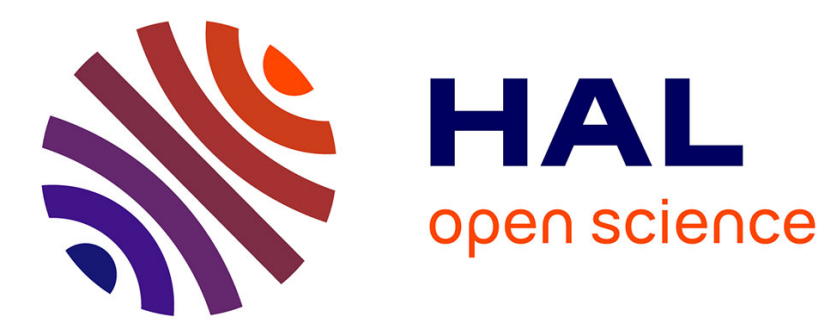

\title{
Outstanding cavitation erosion resistance of Ultra High Molecular Weight Polyethylene (UHMWPE) coatings
}

\author{
Tiana Deplancke, O. Lame, Jean-Yves Cavaillé, Marc C. Fivel, Michel
} Riondet, Jean-Pierre Franc

\section{- To cite this version:}

Tiana Deplancke, O. Lame, Jean-Yves Cavaillé, Marc C. Fivel, Michel Riondet, et al.. Outstanding cavitation erosion resistance of Ultra High Molecular Weight Polyethylene (UHMWPE) coatings. Wear, 2015, 328-329, pp.301-308. 10.1016/j.wear.2015.01.077 . hal-01133748

\section{HAL Id: hal-01133748 \\ https://hal.science/hal-01133748}

Submitted on 8 Sep 2020

HAL is a multi-disciplinary open access archive for the deposit and dissemination of scientific research documents, whether they are published or not. The documents may come from teaching and research institutions in France or abroad, or from public or private research centers.
L'archive ouverte pluridisciplinaire HAL, est destinée au dépôt et à la diffusion de documents scientifiques de niveau recherche, publiés ou non, émanant des établissements d'enseignement et de recherche français ou étrangers, des laboratoires publics ou privés. 


\title{
Outstanding cavitation erosion resistance of Ultra High Molecular Weight Polyethylene (UHMWPE) coatings
}

\author{
Tiana Deplancke ${ }^{\mathrm{a}}$, Olivier Lame ${ }^{\mathrm{a}}$, Jean-Yves Cavaille ${ }^{\mathrm{a}}$, Marc Fivel ${ }^{\mathrm{b}, *}$, \\ Michel Riondet ${ }^{\mathrm{c}}$, Jean-Pierre Franc ${ }^{\mathrm{c}}$ \\ a Université de Lyon, CNRS, INSA-Lyon, MATEIS, UMR5510, F-69621 Villeurbanne, France \\ ${ }^{\mathrm{b}}$ Univ. Grenoble Alpes, CNRS, SIMaP, F-38000 Grenoble, France \\ ${ }^{\mathrm{c}}$ Laboratory of Industrial and Geophysical Flows, Grenoble University, LEGI, BP 53, 38041 Grenoble Cedex 9, France
}

The resistance to cavitation erosion of Ultra High Molecular Weight Polyethylene (UHMWPE) coatings with two molecular weight 0.6 and $10.5 \mathrm{Mg} / \mathrm{mol}$ was tested in a hydrodynamic tunnel during $98 \mathrm{~h}$ at a flow velocity of about $90 \mathrm{~m} / \mathrm{s}$. This polymer is known to have an excellent wear resistance. These materials were processed by sintering on a metallic substrate textured by electron beam melting to ensure mechanical interlocking. UHMWPE with molecular weight $10.5 \mathrm{Mg} / \mathrm{mol}$ has an exceptional resistance to cavitation erosion superior to that of stainless steel A2205 whereas UHMWPE with molecular weight $0.6 \mathrm{Mg} / \mathrm{mol}$ has a resistance to cavitation erosion similar to that of a conventional Nickel Aluminum Bronze alloy (in term of erosion depth). Two possible explanations are put forward for the good cavitation resistance of UHMWPE with highest molecular weight: the tensile test in semicrystalline state shows no strain localization and, above melting temperature, the disentanglement of UHMWPE with molecular weight $10.5 \mathrm{Mg} / \mathrm{mol}$ is very slow unlike the UHMWPE with molecular weight $0.6 \mathrm{Mg} / \mathrm{mol}$ which tends to flow.

\section{Introduction}

Ultra High Molecular Weight Polyethylene (UHMWPE) is known to have exceptional physical and mechanical properties. In particular, it has an excellent wear resistance and is commonly used for total joint implants [1]. It has also an excellent resistance to impacts and is a material of choice for body armors (bullet-proof wet). Its outstanding wear and impact resistance is related to its high ductility. It has a large strain to failure (typically several hundred percent) [2]. Most of semicrystalline polymers exhibit the same ductility, but UHMWPE (with molecular weight above $4 \mathrm{Mg} / \mathrm{mol}$ ) is the only one to propagate deformation without necking probably due to an extremely high content of tie molecules [3,4].

On the other hand, the high molecular weight of UHMWPE gives a very high viscosity to the melt and makes it impossible to be processed by conventional techniques such as injection molding or extrusion. Special fabrication techniques should then be used such as compression molding or sintering.

\footnotetext{
* Corresponding author.

E-mail addresses: tiana.deplancke@insa-lyon.fr (T. Deplancke), Marc.Fivel@simap.grenoble-inp.fr (M. Fivel).
}

Sintering of such viscous polymers with very long chains is a process that requires high time and energetic costs. This is due to the diffusion mechanisms controlled by the reptation time which is proportional to the molecular weight to the power 3 . However recent studies have shown that sintering of UHMWPE nascent powder can be performed in very short time thanks to high velocity compaction [5]. This is due to both "melting explosion" and "co-crystallization" [6]. The UHMWPE sintered can combine outstanding mechanical properties and good process ability. This result has been confirmed for compression molding [2] and opens the way for generalization of the use of UHMWPE.

This paper is devoted to an investigation of the resistance to cavitation erosion of UHMWPE. Very little work has been done on the subject, although several studies are available on the cavitation erosion resistance of non-metallic damping materials such as elastomeric or polymeric coatings. It has been shown that some compliant materials have a good resistance to cavitation erosion that may even exceed that of some metals. Zhang et al. [7], using a rotating disk apparatus, have shown that polyurethane has a better resistance to both cavitation and abrasion by solid particles than $0.45 \%$ carbon steel. Caccese et al. [8] have shown that EPDM (ethylene propylene diene monomer) synthetic rubber has a smaller erosion rate than stainless steel $316 \mathrm{~L}$ according to the ASTM G32 standard test 
procedure. Hattori and Itoh [9] found, using a vibratory device, that HDPE has a much smaller volume loss rate than a low carbon steel (with a tensile strength of more than $400 \mathrm{MPa}$ ). The good cavitation performance of HDPE and UHMWPE was also found by Böhm et al. [10] using an ultrasonic vibratory device.

Hattori and Itoh [9] measured the impact loads due to collapsing cavitation bubbles and found that they are significantly smaller in the case of compliant materials in comparison to stiffer materials. Because of smaller acoustic impedance, the surface of compliant materials undergoes a significant unsteady deformation under cavitation impacts and the amplitude of the impacts is damped accordingly. Their work confirms that the fluid structure interaction is a major issue for compliant materials.

Hattori and Itoh were also able to measure the temperature at a depth of $0.7 \mathrm{~mm}$ below the sample surface during cavitation erosion tests. Their measurements show a significant increase of the specimen temperature for plastics (of the order of $10{ }^{\circ} \mathrm{C}$ ) whereas the internal temperature of metallic alloys increases with only a few degrees. This effect is partly due to the lower conductivity of plastics. Böhm et al. [10] have shown that the polyurethane polymers they tested failed catastrophically by melting rather than fatigue. Other studies on the erosion by solid particles also suggest the local increase of the temperature and the dissipation of the impact energy into heat. This was observed in the case of polymers but not in the case of metals $[11,12]$. Moreover, it is worthy to notice that it is extremely difficult to determine the local and instantaneous temperature. Most of the time, the measured temperature is averaged over a length scale much larger than the impact size (typically a few micrometers) and over a time scale much larger than the impact duration (typically in microseconds). Thermal effects are then expected to play a role in the cavitation erosion resistance of polymers whose melting temperature is relatively small and that could undergo local melting when submitted to strong cavitation impacts.

In this study the cavitation resistance of UHMWPE coating will be tested in a hydrodynamic tunnel at a flow velocity of about $90 \mathrm{~m} / \mathrm{s}$. This test was stopped several times to allow for measurement of mass loss by profilometry and images by electron microscopy after different exposure times. The results of these tests will be then compared to the cavitation resistance of conventional metallic materials.

\section{Experimental procedure}

\subsection{Sample fabrication}

Conventional processing techniques are not possible for UHMWPE due to the very high viscosity of the melt phase. As a consequence, processed inspired from powder metallurgy such as sintering have been developed [2].

The material used a nascent powder of UHMWPE produced by TICONA. The molecular weights chosen for this study are 0.6 and $10.5 \mathrm{Mg} / \mathrm{mol}$. These molecular weights are given by the powder manufacturer (Ticona) and deduced from viscosity measurements. The average grain size is $150 \mu \mathrm{m}$ and the statistical distribution extends from 50 to $500 \mu \mathrm{m}$, as measured by the laser scattering technique [13].

Sintering of UHMWPE is performed in an Instron (c) compressive machine equipped with a Servantin oven (Fig. 1). Sintering of UHMWPE can be separated in 3 stages. The first one is the densification of the powder, under a vacuum. Densification is performed below melting temperature $\left(T_{\mathrm{m}} \approx 135^{\circ} \mathrm{C}\right)$ in order to prevent chain diffusion. The powder sample is heated for $10 \mathrm{~min}$ at $80^{\circ} \mathrm{C}$ under a pressure of $80 \mathrm{MPa}$ and a vacuum of about 10 mbar. According to many authors [14-16], this step is very important for the efficiency of the interface welding. The porosity of the sintered material can have a dramatic

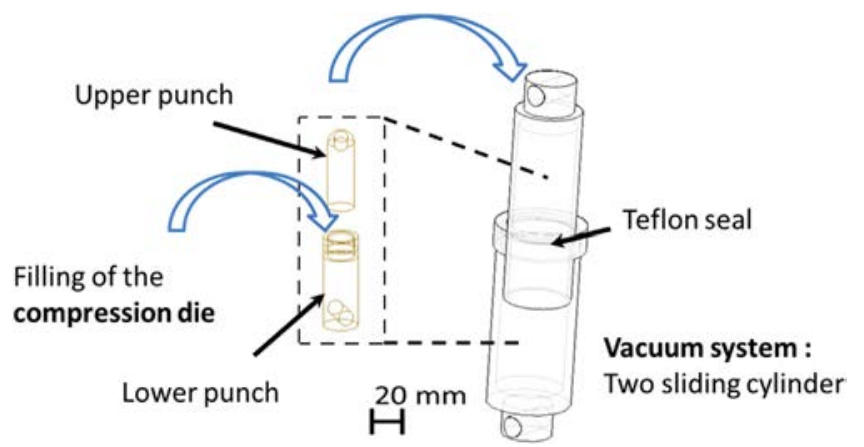

Fig. 1. View of the sintering device consists of a compression die inside a vacuum system which allows applying the pressure on the two punches while keeping the vacuum.

effect on its mechanical properties. Thus, the densification conditions were empirically optimized and validated by density measurements [2]. Density measurements were performed using the buoyancy method based on Archimedes' principle. After unloading, the density of the densified disc is equal to $0.94 \mathrm{~g} / \mathrm{cm}^{3}$ in the case of the molecular weight $0.6 \mathrm{Mg} / \mathrm{mol}$ and $0.92 \mathrm{~g} / \mathrm{cm}^{3}$ in the case of the molecular weight $10.5 \mathrm{Mg} / \mathrm{mol}$. These value are compared to the theoretical density obtained from crystallinity (62\% for the molecular weight $0.6 \mathrm{Mg} / \mathrm{mol}$ and $38 \%$ for $10.5 \mathrm{Mg} / \mathrm{mol}$ given in mass) computed from DSC (Differential Scanning Calorimetric), taking $\rho_{\mathrm{a}}=0.855 \mathrm{~g} / \mathrm{cm}^{3}$ and $\rho_{\mathrm{c}}=1.000 \mathrm{~g} / \mathrm{cm}^{3}$ for the densities of the amorphous and the crystalline phases, respectively. Lack of pore in the size range $1-60 \mathrm{~nm}$ was checked by a Small Angle Scattering. Thus, the contact between the grains can be considered excellent.

The second step of the process is the consolidation of interfaces by chain diffusion across interfaces, above melting temperature to allow the movements of chains. This second step is the basic one for consolidation of interfaces by chain re-entanglement. The densified sample is heated at $200{ }^{\circ} \mathrm{C}$ during $2 \mathrm{~h}$.

For semi-crystalline polymers, it is also possible to consolidate the interfaces by co-crystallization after chain diffusion $[2,5,16,17]$. Co-crystallization consists in growing new crystallites across the interface binding the initial powder particles. For the final step, the sample is cooled down to room temperature under a $20 \mathrm{MPa}$ pressure in order to prevent shrinkage cracks.

To ensure a good adhesion of the polymer on a metallic substrate, the substrate surface has been textured by an electron beam melting (EBM). Using this additive manufacturing technique, a 2D assembly of tetracaidecahedrons of radius $0.5 \mathrm{~mm}$ has been built on top of a bulk cylinder of TiAl (conventional material for the EBM) of radius $21 \mathrm{~mm}$ and height $4 \mathrm{~mm}$. The shape of the architectured surface creates mechanical traps for the polymer powder. After the sintering stage, the polymer is strongly locked inside the metallic frame which creates a good adhesion of the polymer. During all the experiments presented in this paper, no debonding has been observed. Fig. 2 shows schematic views and photographs of the UHMWPE samples.

\subsection{Cavitation tests}

Cavitation tests were conducted in a hydrodynamic tunnel whose characteristics are presented in detail in Refs. $[18,19]$. The facility is designed for a maximum operating pressure of $4 \mathrm{MPa}$. This relatively high pressure provides high velocities, and consequently, high erosive potential for the cavitating flow. The test section is axisymmetric and the inlet is made of a nozzle of $16 \mathrm{~mm}$ in diameter (see Fig. 4). The samples to be tested are mounted on a holder of $100 \mathrm{~mm}$ in diameter (see Fig. 4) facing the nozzle at a distance of $2.5 \mathrm{~mm}$. Cavitation takes the form of an axisymmetric cavity attached to the nozzle outlet. Maximum erosive potential is observed in the closure region of the 

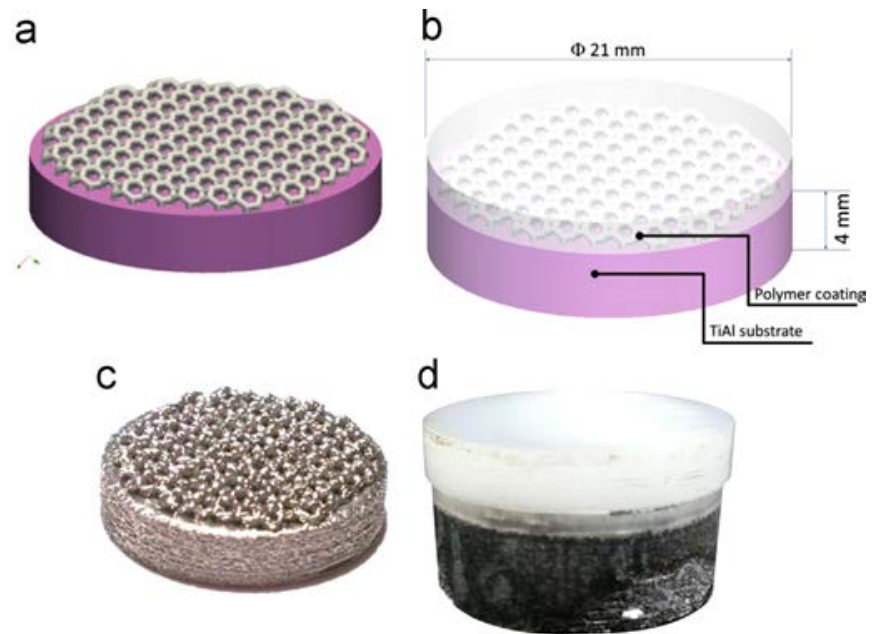

Fig. 2. Views of the substrate/coating system. (a) and (b): Schematic view and photograph of the substrate. (c) and (d): Schematic view and photograph of a coated sample.

cavity and cavitation erosion damage has a ring type shape clearly visible in Fig. 4. Samples are mounted at a radial distance that corresponds approximately to the ring radius. Then, all samples are subjected to the same erosive flow and could be compared. All cavitation erosion tests presented in this paper were conducted at an upstream pressure $p_{\mathrm{u}} \approx 4 \mathrm{MPa}$, a downstream pressure $p_{\mathrm{d}} \approx 1.86 \mathrm{MPa}$ and a cavitation number $\sigma=p_{\mathrm{d}} /\left(p_{\mathrm{u}}-p_{\mathrm{d}}\right) \approx 0.87$. Visualizations of the flow [20] clearly show that the instantaneous flow is not axisymmetric and the cavitation is strongly unsteady. It is characterized by the development of a cavity that sheds more or less regularly vapor structures by a re-entrant jet mechanism.

Nevertheless, the mean flow can be considered as very axisymmetric. This is visible on pitting tests that show that the distribution of pits is statistically independent of the azimuthal angle. This is because the exposure time (even though it may be short of the order of one minute only) is much longer than the characteristic time of the shedding mechanism. In other words, even though the instantaneous flow is not axisymmetric, the resulting damage is axisymmetric. Moreover, the sample holder is rotated before each new test in order to limit potential axisymmetric problems. The exposure time was gradually increased up to $98 \mathrm{~h}$. On the $100 \mathrm{~mm}$ sample holder, six UHMWPE samples with $21 \mathrm{~mm}$ in diameter were flush mounted in the zone of maximum erosion: three with molecular weight $0.6 \mathrm{Mg} / \mathrm{mol}$ and three with molecular weight $10.5 \mathrm{Mg} / \mathrm{mol}$ (see Fig. 4). For each of the molecular weights, three thicknesses of polymers were tested, 2, 3 and $4 \mathrm{~mm}$. Additional information on the facility is available in Ref. [18].

\section{Initial damage}

This section is devoted to a description of the initial stage of damage on UHMWPE. For relatively short exposure times for which no significant material removal occurs (see Section 4.2), damage appears mostly as isolated pits. As an example, Fig. 3 shows SEM pictures of the virgin surface (Fig. 3a) and typical pits, after an exposure time of 20 min (Fig. 3b and c). Pit size is on the order of a few tens of micrometers as can be seen in Fig. 3. It is significantly smaller than the grain size $(150 \mu \mathrm{m}$ on average), so that it can be concluded that this type of damage does not correspond to the removal of a grain as a whole. During the early stage of erosion, cavitation damage on UHMWPE is very similar to damage on ductile metallic alloys that shows plastic deformations of similar size [21]. Each pit is expected to be due to the collapse of a single cavitation bubble.
Moreover, SEM observations showed that, when moving along the flow direction, pit density first increases, shows a maximum and then vanishes downstream. Furthermore, the largest pits occur preferably in the downstream part of the eroded region. These observations of the early stage of erosion on UHMWPE are consistent with usual observations derived from pitting tests on metallic alloys. The occurrence of larger pits in the downstream part of the eroded region may be associated to larger bubbles that have a longer lifetime and then collapse more downstream $[22,23]$.

In Fig. 3, we can observe fracture surface like ductile rupture [24] and a pile-up suggests a plastic deformation. The observed fibrils show a torn matter (see arrow in Fig. 3c) and suggests that the material has been heated and maybe partially melted [13]. Given the high speed of cavitation tests, the material is necessarily heated during the time of the impact but in extremely short times and over a range of temperature that cannot be determined precisely. It is also clear that fracture has occurred leading to loss of matter.

\section{Advanced stages of erosion}

\subsection{Observation of eroded surfaces}

Fig. 4 is a picture of the samples after $98 \mathrm{~h}$ exposure to the cavitating flow. The three samples with the molecular weight $0.6 \mathrm{Mg} / \mathrm{mol}$ have severe erosion damage whereas, in the case of the samples with molecular weight $10.5 \mathrm{Mg} / \mathrm{mol}$, the damage due to erosion by cavitation is negligible.

No clear effect of coating thickness is visible in Fig. 4. This observation is confirmed by profilometry measurements shown in Figs. 6 and 7. The erosion profiles shown in these curves are measured in the central part of the UHMWPE samples where it can be expected that the boundary effects relevant to the interface with the holder are negligible.

To complete these observations, SEM images with different magnifications are shown in Fig. 5. These images were taken in the area of maximum damage and were chosen as most representative of the eroded area. They concern a long exposure time (98 h) i.e. an advanced stage of erosion for which this area has received numerous impacts of various energy. They show that the collapse of cavitation bubbles causes torn matter by successive layers. The damage mechanism appears to be similar for the two molecular weights. In particular, for the high magnification (Fig. 5e and f), several steps are visible suggesting that the damage is done in stages with a gradual peeling off of successive layers of material.

In the case of the lower molecular weight $(0.6 \mathrm{Mg} / \mathrm{mol})$, wrenching of layers is so important that very fine filaments cover the surface (Fig. 5d) while larger and less stretched flakes appear for the large molecular weight $(10.5 \mathrm{Mg} / \mathrm{mol})$. These observations are consistent with previous observations showing that UHMWPE with molecular weight $0.6 \mathrm{Mg} / \mathrm{mol}$ is less resistant to cavitation than the one with molecular weight $10.5 \mathrm{Mg} / \mathrm{mol}$. To complete these observations, quantitative measurements by profilometry are presented in the next section.

\subsection{Radial profiles of erosion damage}

Fig. 6 shows radial profiles of erosion damage in the case of a sample with molecular weight $0.6 \mathrm{Mg} / \mathrm{mol}$ and with $2 \mathrm{~mm}$ in thickness. Each curve is shifted to separate the profiles corresponding to different exposure times. For each exposure time, two profiles are plotted. One is the measured raw profile that may present a significant roughness. A smoothed profile is superimposed using a $1 \mathrm{~mm}$ sliding average procedure. 

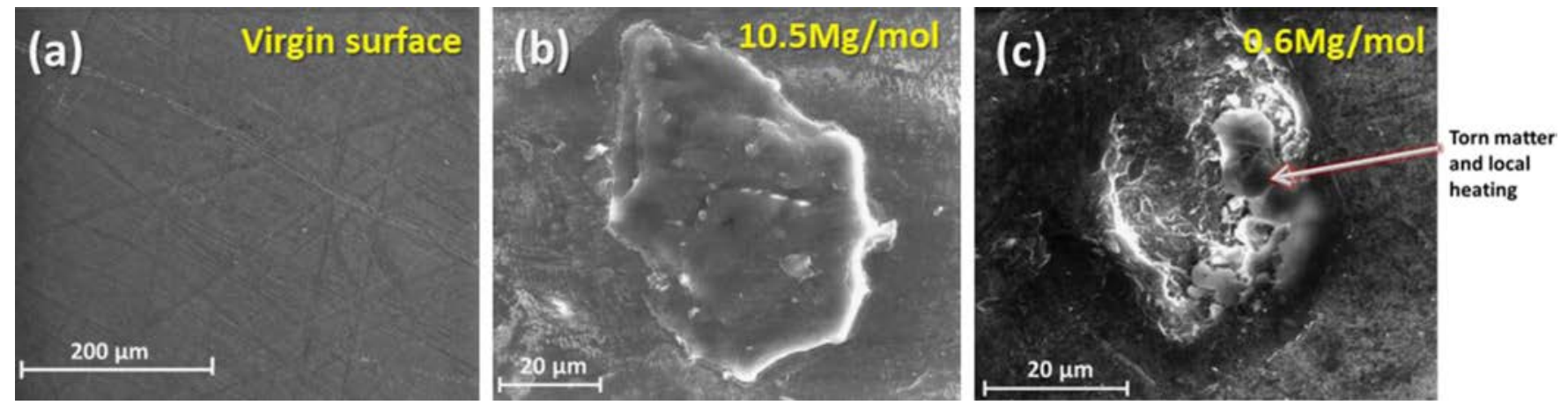

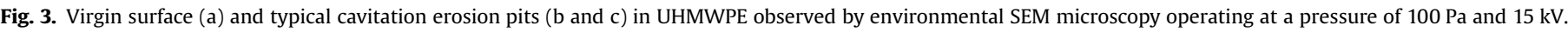
The sample has been exposed to the cavitating flow during 20 min (erosion tests under 40 bars with cavitation number 0.87 ).

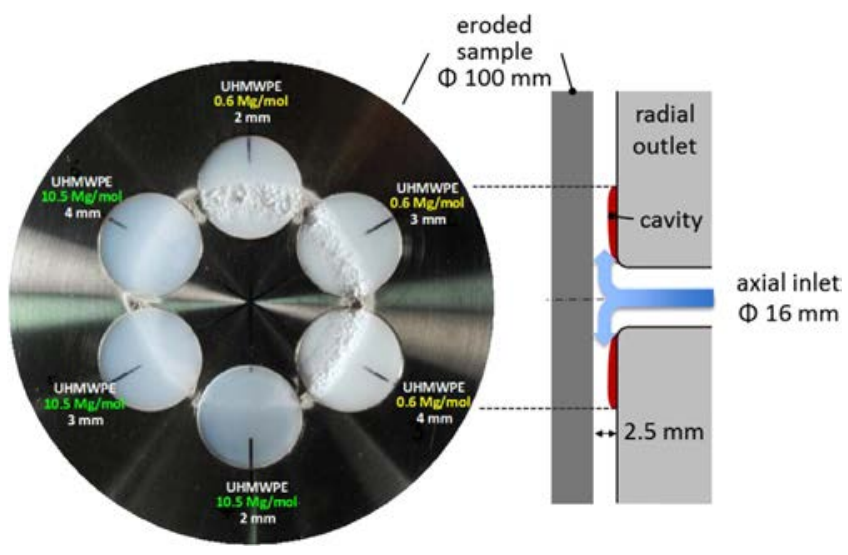

Fig. 4. View of six samples of UHMWPE tested simultaneously in the cavitation tunnel and the schematic view of the cavitation system. The samples have been exposed to the cavitating flow during $98 \mathrm{~h}$. The diameter of each sample is $21 \mathrm{~mm}$ and the diameter of the sample holder is $100 \mathrm{~mm}$. Two molecular weights have been tested: 0.6 and $10.5 \mathrm{Mg} / \mathrm{mol}$ with three thicknesses: 2,3 and $4 \mathrm{~mm}$. Sintering lasted $2 \mathrm{~h}$ at $200^{\circ} \mathrm{C}$. Erosion test conditions are 40 bar with a cavitation number of 0.87 .

The profiles have been measured using a contact profilometer with a stylus tip radius of $2 \mu \mathrm{m}$. They have been measured over a distance of $30 \mathrm{~mm}$ with a horizontal resolution of $1 \mu \mathrm{m}$.

For short exposure times, typically shorter than $24 \mathrm{~h}$, erosion damage is characterized by an overall depression of small depth that reaches about $30 \mu \mathrm{m}$ after $24 \mathrm{~h}$ exposure time. This shallow depression results from the accumulation of pits as shown in Section 3 with an increasing probability of overlapping with increasing exposure time.

Critical erosion damage, with substantial weight loss starts after $30 \mathrm{~h}$ exposure time. From this time on, mean depth of erosion increases significantly and reaches about $500 \mu \mathrm{m}$ after $98 \mathrm{~h}$. Two different regimes of erosion are then clearly identified for UHMWPE with the smaller molecular weight. For small exposure times, cavitation erosion damage remains limited whereas it drastically increases after a critical exposure time on the order of $30 \mathrm{~h}$ for the present cavitating conditions.

Note that the location of the maximum erosion seems to move a few millimeters upstream. It can reasonably be expected that the change of the wall geometry due to material removal impacts the cavitating flow and consequently the progress of erosion. This could also explain the loss of symmetry observed in the erosion pattern for long exposure times.

Fig. 7 shows radial profiles of erosion damage in the case of samples with molecular weight $10.5 \mathrm{Mg} / \mathrm{mol}$ and with $2 \mathrm{~mm}$ in thickness. Even after an exposure time of $98 \mathrm{~h}$, the erosion damage
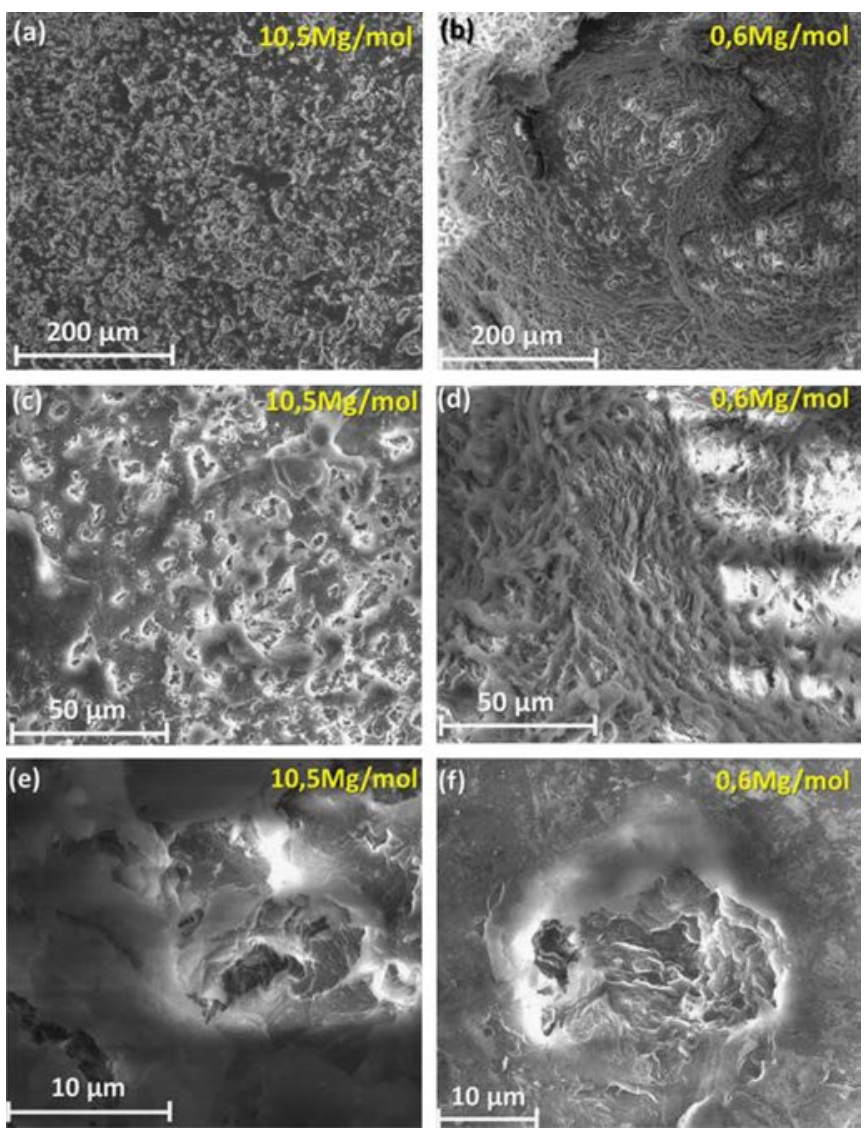

Fig. 5. Typical cavitation erosion damage in UHMWPE observed by environmental SEM microscopy under a pressure of $100 \mathrm{~Pa}$ and $15 \mathrm{kV}$. The samples have been exposed to the cavitating flow during $98 \mathrm{~h}$.

is very low. Only the first regime of erosion identified previously occurs on the UHMWPE samples with the largest molecular weight. The second regime characterized by a larger erosion rate is not observed here. From the present tests, it is not possible to conclude whether the second regime may develop after a larger critical time or whether it will never develop in this cavitating flow of given aggressiveness whatever maybe the exposure time. In the latter case, it can however be conjectured that the second regime would develop anyway in a cavitating flow of larger aggressiveness. A correlation between critical time and flow aggressiveness could then be expected. To address this issue, erosion tests of longer duration and/or different aggressiveness are required. Nevertheless, the present erosion tests definitely show that erosion resistance of UHMWPE strongly depends upon molecular weight. 


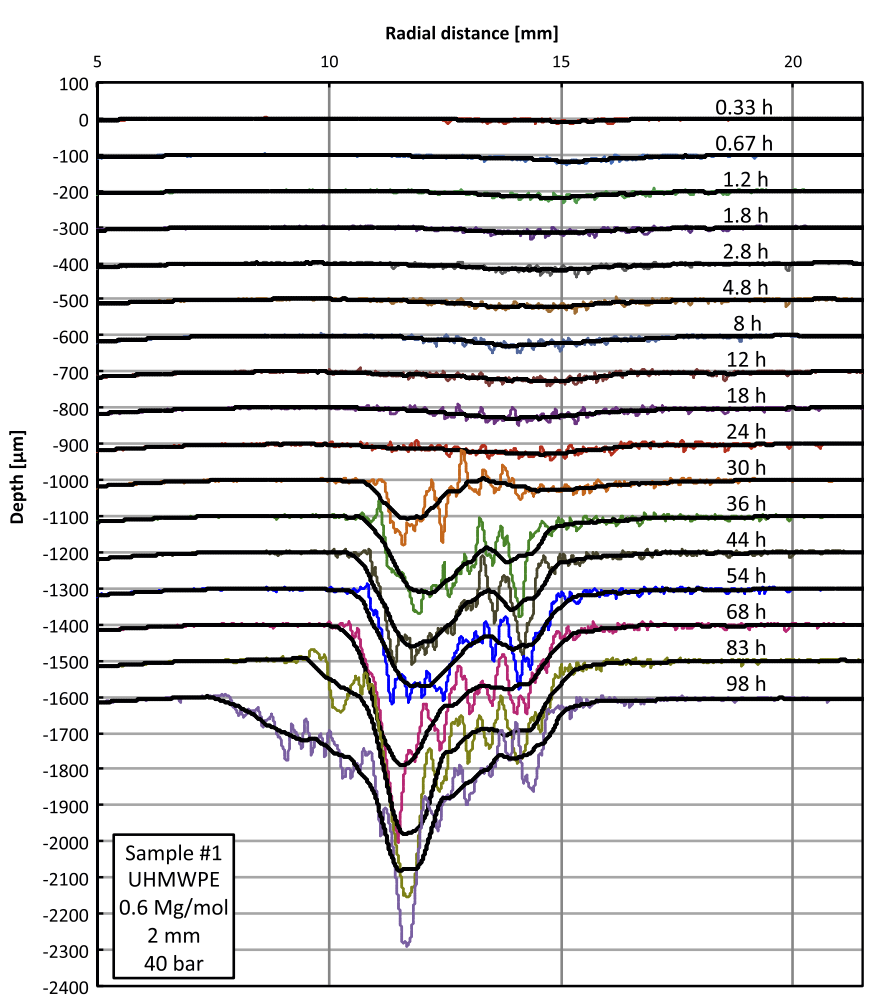

Fig. 6. Surface profiles of a typical UHMWPE sample (molecular weight $0.6 \mathrm{Mg}$ / mol; thickness $2 \mathrm{~mm}$ ) plotted along the radial direction at various exposure time. Each curve is shifted to separate the profiles corresponding to different exposure times (Erosion test performed under 40 bar with cavitation number 0.87 ).

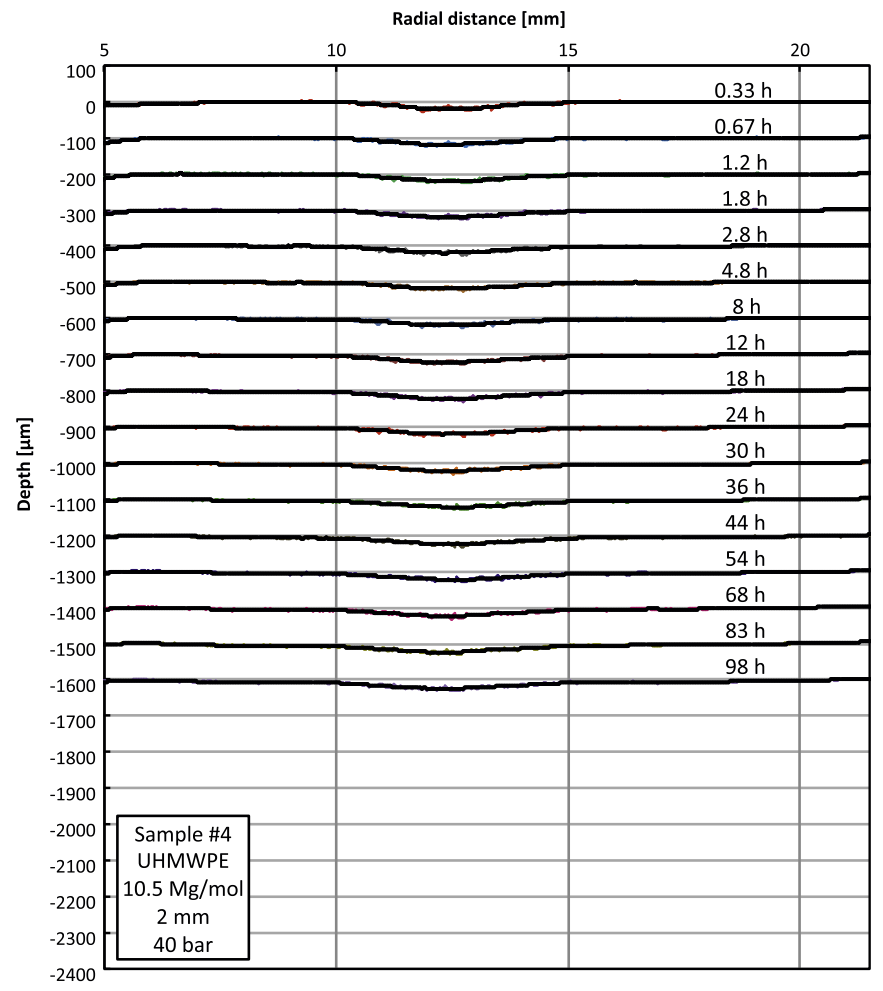

Fig. 7. Surface profiles of a typical UHMWPE sample (molecular weight $10.5 \mathrm{Mg}$ / mol; thickness $2 \mathrm{~mm}$ ) plotted along the radial direction at various exposure time. Each curve is shifted to separate the profiles corresponding to different exposure times (Erosion test performed under 40 bar ( $4 \mathrm{MPa}$ ) with cavitation number 0.87 ).

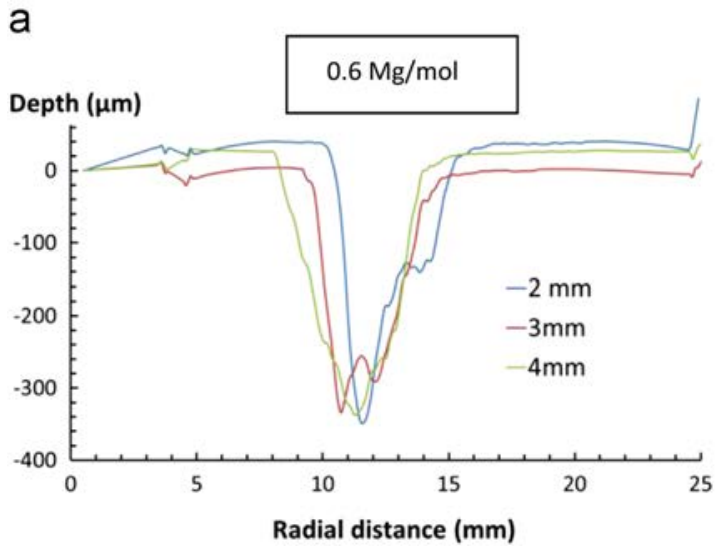

b

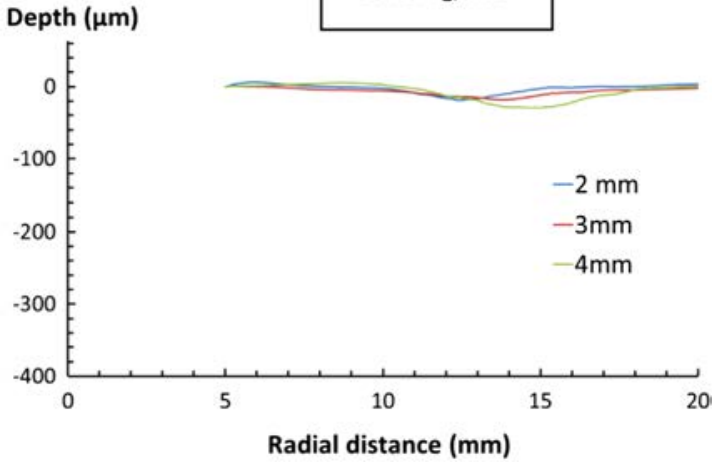

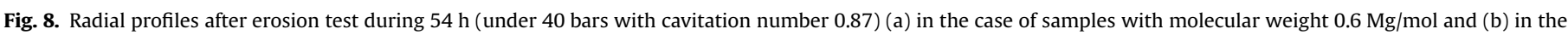
case of samples with molecular weight $10.5 \mathrm{Mg} / \mathrm{mol}$ for different thicknesses of the coating polymer.

To check the influence of polymer coating thickness, Fig. 8 shows radial profiles after an exposure time of $54 \mathrm{~h}$ for different thicknesses of polymer, 2, 3 and $4 \mathrm{~mm}$. The thickness of polymer coating does not appear to affect damage in the investigated range. As expected, the polymeric coating behaves like a bulk material.

Simple computations by the finite element method of the response of a UHMWPE coating/substrate system have been made in order to estimate the critical thickness below which the coating no longer behaves like a bulk material. The most important parameter is the radial extent of the pressure distribution generated by the bubble collapse. If the coating thickness is significantly larger than the radius of the applied pressure distribution, the deepest part of the coating does not feel the impact and the coating behaves like a bulk material. Since the radius of the pressure distribution is typically of a few hundreds of micrometers at the most for the present cavitation device [25], this confirms that no thickness effect is found in the present work for which thicknesses are larger than $2 \mathrm{~mm}$.

\subsection{Kinetics of erosion}

Fig. 9 shows the erosion depth as a function of exposure time. The erosion depth plotted in Fig. 9 is the maximum depth estimated from smoothed profiles (see Section 4.2). In the case of the small molecular weight $(0.6 \mathrm{Mg} / \mathrm{mol})$, a plateau is observed up to a critical exposure time lying between $12 \mathrm{~h}$ and $30 \mathrm{~h}$ depending upon the tested sample. From this critical time, the erosion damage increases dramatically. 


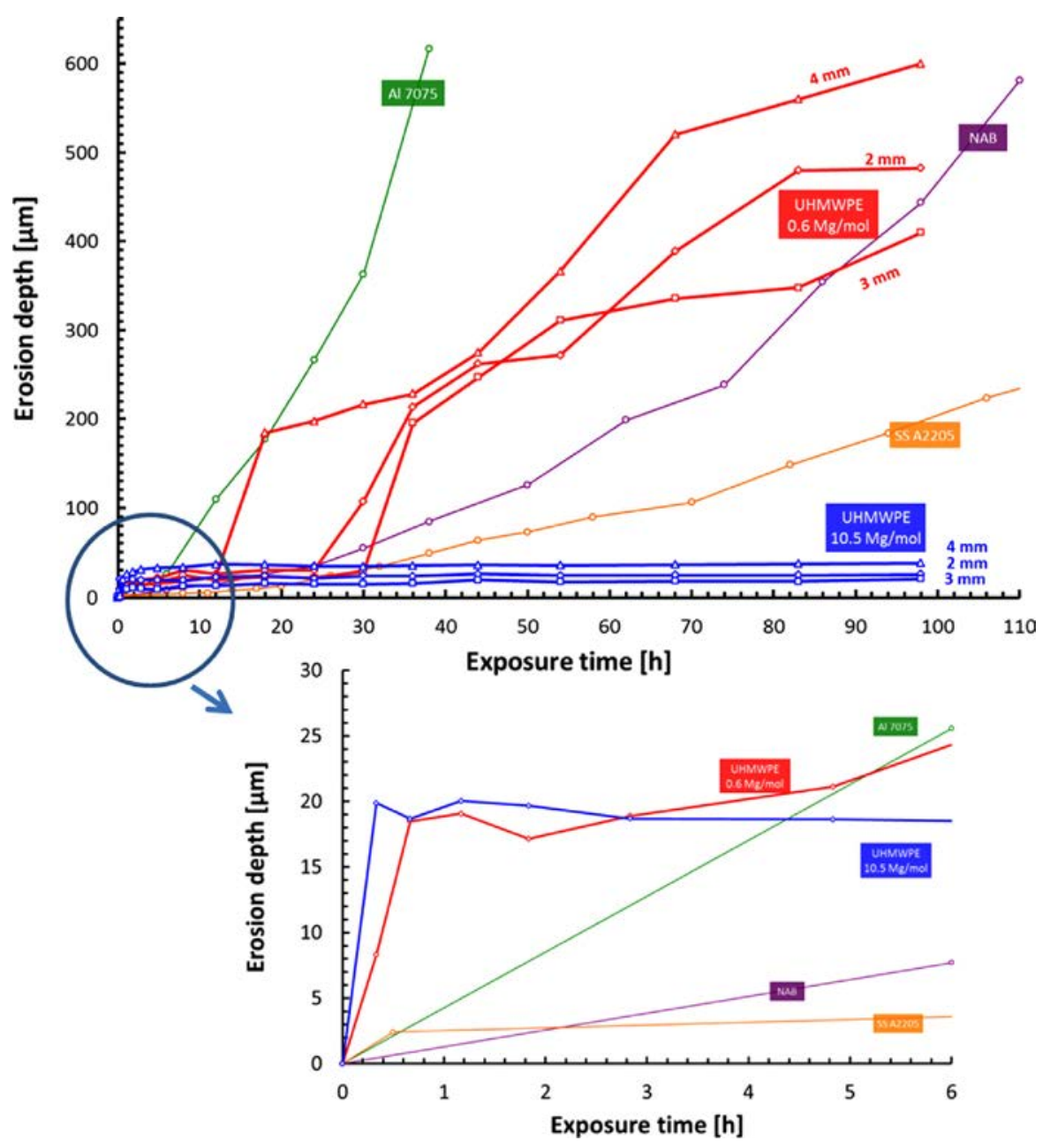

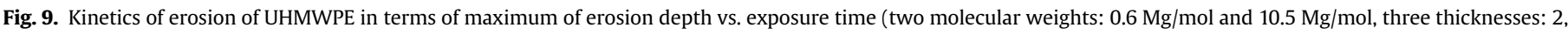

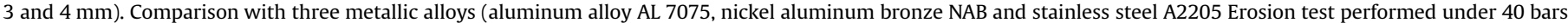
with cavitation number 0.87 ).

In the case of the large molecular weight $(10.5 \mathrm{Mg} / \mathrm{mol})$, the plateau is much longer and the critical time for the onset of the second regime mentioned above was not observed. No significant erosion damage is observed until the maximum exposure time of $98 \mathrm{~h}$.

For comparison, Fig. 9 also shows the erosion depth curves obtained, under exactly the same operating conditions, for three metallic alloys: aluminum alloy Al 7075, Nickel Aluminum Bronze (NAB) alloy and stainless steel A2205 (stainless ferritic-austenitic $\mathrm{Cr}-\mathrm{Ni}$-Mo steel with nitrogen addition). UHMWPE $(0.6 \mathrm{Mg} / \mathrm{mol})$ lies in between the aluminum and the NAB alloys. On the contrary, UHMWPE $(10.5 \mathrm{Mg} / \mathrm{mol})$ shows a much better resistance to cavitation erosion than stainless steel A2205.

As seen in the zoom shown in Fig. 9, at the beginning of the erosion test (typically during a few tens of minutes), the depth increases rapidly, which indicates a relatively large initial erosion rate, on the order of a few tens of micrometers per hour. This result suggests a pre-crushing due to plastic deformation and piling-up of material on the sides of cavitation impacts.

Then, the erosion rate decreases very significantly and reaches a plateau with a much smaller increase of damage with time, typically smaller than $1 \mu \mathrm{m} / \mathrm{h}$. In other words, after an initial period with a relatively large erosion rate, the damage seems to saturate. This behavior is drastically different from that of metallic alloys that generally exhibit an incubation period with negligible mass loss followed by an acceleration period with a gradual increase of the erosion rate up to a maximum value when a steady-state regime of erosion is reached.

\section{Discussion}

In a first approach, the different behaviors of the two UHMWPE with different molecular weights are analyzed on the basis of tensile tests, above and below the melting temperature. Indeed, due to its very long chain, UHMWPE has an extremely broad rubbery plateau that extends from $140{ }^{\circ} \mathrm{C}$ to $300{ }^{\circ} \mathrm{C}$. This exceptional property enables to perform tensile experiments below as well as above the melting temperature $\left(T_{m} \sim 140^{\circ} \mathrm{C}\right)$.

All tensile tests have been performed using a tensile machine MTS $^{\odot} 1 / \mathrm{ME}$ equipped with a MTS (C) CE412 oven. The tensile machine was fitted with two kinds of load cells, one having a $5 \mathrm{kN}$ range for tensile tests at room temperature and the other one having a $100 \mathrm{~N}$ range for tensile tests at $150{ }^{\circ} \mathrm{C}$.

For the tensile tests at room temperature the cross-head speed was $2 \mathrm{~mm} / \mathrm{min}$, so that the initial strain rate was $3.5 \times 10^{-3} \mathrm{~s}^{-1}$. For the tensile tests at $150{ }^{\circ} \mathrm{C}$, the cross-head speed was $6 \mathrm{~mm} / \mathrm{min}$, thus the initial strain rate was $10^{-2} \mathrm{~s}^{-1}$. The sample temperature was checked by means of a thermocouple glued to the head of the tensile specimen. The temperature difference over the sample length did not exceed $3{ }^{\circ} \mathrm{C}$. 


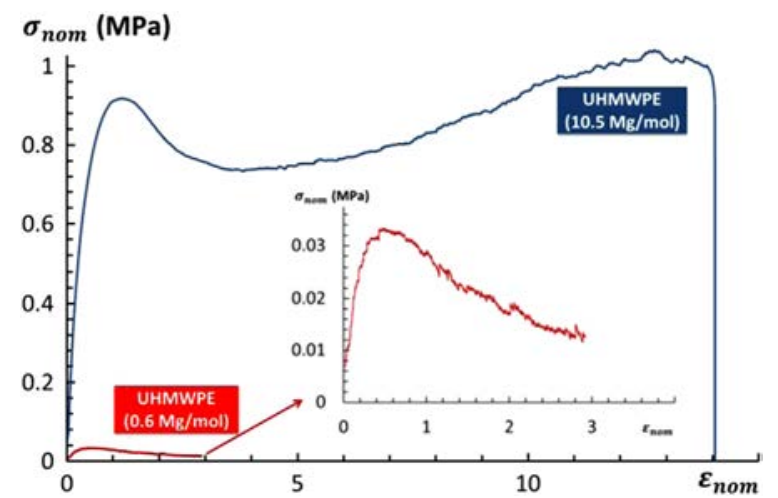

Fig. 10. Nominal stress-strain curves of UHMWPE obtained from tensile tests at $150{ }^{\circ} \mathrm{C}$ (above melting temperature). Comparison of UHMWPE with molecular weight $0.6 \mathrm{Mg} / \mathrm{mol}$ and $10.5 \mathrm{Mg} / \mathrm{mol}$. The insert is given to focus on the stressstrain curves of UHMWPE with molecular weight $0.6 \mathrm{Mg} / \mathrm{mol}$.

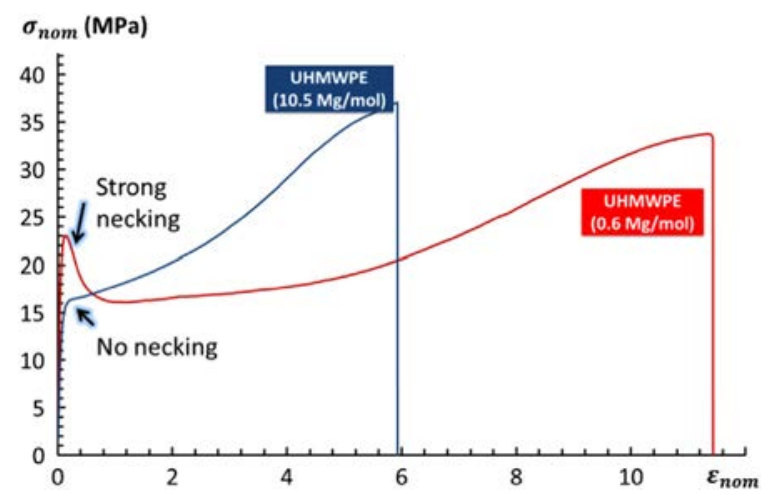

Fig. 11. Nominal stress-strain curves obtained from tensile tests at room temperature.

The nominal strain was computed as $\varepsilon_{\text {nom }}=L / L_{\mathrm{o}}$, where $L_{\mathrm{o}}$ is the initial sample gauge length and $L$ its length under strain. The nominal stress was defined as $\sigma_{\text {nom }}=F / S_{o}$ where $F$ is the tensile force and $S_{\mathrm{o}}$ the initial sample cross-section.

Tensile tests performed at $150{ }^{\circ} \mathrm{C}$ (Fig. 10) allow focusing on the macromolecules re-entanglement because all crystallites have melted at this temperature; this material is then a rubber. These tests show that the mechanical properties of the polymer with molecular weight $0.6 \mathrm{Mg} \mathrm{mol}^{-1}$ are extremely bad, while the properties of the polymer with molecular weight $10.5 \mathrm{Mg} \mathrm{mol}^{-1}$ remain quite good, with in particular a strain at failure higher than $1000 \%$. This difference is explained by the fact that UHMWPE with molecular weight $0.6 \mathrm{Mg} / \mathrm{mol}$ is close to the conventional polyethylene that tends to flow during tensile tests. Indeed flowing of a polymeric material is explained by the disentanglement of chains in a time shorter than the time of the experiment. The longer the chains, the larger the number of entanglements by chain, and therefore the more difficult it is to disentangle. This explains qualitatively the better mechanical properties of UHMWPE above melting temperature [2].

At room temperature, both the crystalline structure and the entanglement network contribute to the mechanical properties. The stress-strain curves (Fig. 11) show that crystal network and cocrystallization are, at room temperature, the dominant phenomena in the mechanical characteristics of sintered UHMWPE. The sample with molecular weight $0.6 \mathrm{Mg} / \mathrm{mol}$ has the best strain at failure and the largest energy before fracture (area under the stress-strain curve). The differences between the two molecular weights are due to crystallinity which is significantly greater in the case of the lower molecular weight $(0.6 \mathrm{Mg} / \mathrm{mol})$. Indeed the degree of crystallinity in the case of molecular weight $0.6 \mathrm{Mg} / \mathrm{mol}$ is about $62 \%$ (measured by DSC) and is no more than $38 \%$ in the case of molecular weight $10.5 \mathrm{Mg} / \mathrm{mol}$ [13].

The results of cavitation erosion tests are not consistent with the results of tensile tests at room temperature since UHMWPE with molecular weight $0.6 \mathrm{Mg} / \mathrm{mol}$ has better mechanical properties but exhibits more severe cavitation erosion damage. On the contrary, they appear to be consistent with mechanical properties above melting temperature. This observation suggests that thermal effects may arise locally during the impact generated by the collapse of a cavitation bubble or the dissipation of the impact energy into heat [11].

Moreover, Fig. 11 shows necking in the case of the lower molecular weight, indicating a significant localization of stress, whereas no necking occurs in the case of the higher molecular weight. Stress localization may be a second possible explanation of the different cavitation resistance of the two UHMWPE. In fact, tied molecules prevent semi-crystalline polymers from necking $[3,4,26]$. As a result, the strain energy is not concentrated into a small volume leading to fracture. It involves a larger volume so that the peak stress does not easily reach the fracture stress.

\section{Summary and conclusion}

In order to improve cavitation erosion resistance, polymeric coatings may be used. In the present paper, the choice was focused on UHMWPE which is known to have excellent resistance to impact. Two molecular weights were tested: $0.6 \mathrm{Mg} / \mathrm{mol}$ and $10.5 \mathrm{Mg} / \mathrm{mol}$.

UHMWPE was processed by sintering because conventional processing of UHMWPE is nearly impossible due to its very high viscosity in the melt phase. Adhesion between the metallic substrate and the polymer coating was achieved using a substrate textured by electron beam melting ensuring that the polymer is mechanically attached to the substrate. The resistance to cavitation erosion of several UHMWPE polymeric samples was tested in a hydrodynamic tunnel during $98 \mathrm{~h}$ at a flow velocity of about $90 \mathrm{~m} / \mathrm{s}$.

UHMWPE with molecular weight $10.5 \mathrm{Mg} / \mathrm{mol}$ shows an exceptional resistance to cavitation erosion superior to that of UHMWPE with molecular weight $0.6 \mathrm{Mg} / \mathrm{mol}$. According to SEM observation, the damage mechanism appears to be similar for both types of UHMWPE, and consists of peeling of the material, layer after layer. Volume loss measurements estimated by contact profilometry at different exposure times, show that the UHMWPE with molecular weight $0.6 \mathrm{Mg} / \mathrm{mol}$ has a resistance to cavitation erosion close to that of a conventional Nickel Aluminum Bronze alloy. On the other hand, UHMWPE with molecular weight $10.5 \mathrm{Mg} / \mathrm{mol}$ shows negligible mass loss significantly smaller than that of stainless steel A2205 after an exposure time of $98 \mathrm{~h}$. The thickness of the polymer coating does not appear to affect damage in the investigated range from $2 \mathrm{~mm}$ to $4 \mathrm{~mm}$.

To analyze the different resistance to cavitation erosion of these two polymeric materials, tensile tests were conducted above and below the melting temperature. Two alternative explanations are proposed, namely (i) a significant local temperature increase up to melting temperature under cavitation impacts, or/and (ii) localized deformation in the case of the lower molecular weight, which would result in a greater damage.

\section{Acknowledgments}

The authors are indebted to Ticona (Oberhausen, Germany) for the generous supply of the UHMWPE sample together with its molecular characteristics. 
Authors would also like to thank the Office of Naval Research (ONR, USA) and ONR Global for their financial support through the Naval International Cooperative Opportunities in Science \& Technology Program (NICOP, Grant No. N62909-12-1-7112).

\section{References}

[1] J. Fu, et al., Ultra high molecular weight polyethylene with improved plasticity and toughness by high temperature melting, Polymer 51 (12) (2010) 2721-2731.

[2] T. Deplancke, et al., Diffusion versus cocrystallization of very long polymer chains at interfaces: experimental study of sintering of UHMWPE nascent powder, Macromolecules 47 (1) (2013) 197-207.

[3] S. Humbert, O. Lame, G. Vigier, Polyethylene yielding behaviour: what is behind the correlation between yield stress and crystallinity? Polymer 50 (15) (2009) 3755-3761.

[4] C. Bonten, E. Schmachtenberg, A new hypothesis to describe the mechanisms acting in a welded joint of semicrystalline thermoplastics, Polym. Eng. Sci. 41 (3) (2001) 475-483.

[5] D. Jauffres, et al., Sintering mechanisms involved in high-velocity compaction of nascent semicrystalline polymer powders, Acta Mater. 57 (8) (2009) 2550-2559.

[6] D. Jauffrès, et al., Yield, creep, and wear properties of ultra high molecular weight polyethylene processed by high velocity compaction, J. Appl. Polym. Sci. 110 (5) (2008) 2579-2585.

[7] J. Zhang, et al., Assessment of resistance of non-metallic coatings to silt abrasion and cavitation erosion in a rotating disk test rig, Wear 194 (1) (1996) 149-155.

[8] V. Caccese, K. Light, K. Berube, Cavitation erosion resistance of various material systems, Ships Offshore Struct. 1 (4) (2006) 309-322.

[9] S. Hattori, T. Itoh, Cavitation erosion resistance of plastics, Wear 271 (7) (2011) $1103-1108$

[10] H. Böhm, S. Betz, A. Ball, The wear resistance of polymers, Tribol. Int. 23 (6) (1990) 399-406.
[11] P.H. Shipway, D.P. Weston, Thermal effects in blasting and erosion of polymeric materials, J. Mater. Process. Technol. 209 (2009) 6161-6167.

[12] D.R. Andrews, An analysis of solid particle erosion mechanisms, Journal of Physics D: Applied Physics 14 (11) (1981) 1979.

[13] T., Deplancke, Approche des mécanismes de frittage du UHMWPE: étude du comportement mécanique à l'état solide et à l'état fondu, INSA de Lyon, 2013.

[14] Y.H. Kim, R.P. Wool, A theory of healing at a polymer polymer interface, Macromolecules 16 (7) (1983) 1115-1120.

[15] R.P. Wool, K.M. Oconnor, A theory of crack healing polymers, J. Appl. Phys. 52 (10) (1981) 5953-5963.

[16] Y.Q. Xue, et al., Welding behavior of semicrystalline polymers 2. Effect of cocrystallization on autoadhesion, Macromolecules 33 (19) (2000) 7084-7087.

[17] C. Frederix, et al., Kinetics of the non-isothermal fusion-welding of unlike ethylene copolymers over a wide crystallinity range, Polymer 54 (11) (2013) 2755-2763.

[18] J.-P. Franc, Incubation time and cavitation erosion rate of work-hardening materials, J. Fluids Eng. 131 (2) (2009) 021303.

[19] K.-H.C. Kim, G. Chahine, J.P. Franc, A. Karimi, Advances experimental and numerical techniques for cavitation erosion prediction, Fluid Mechanics and its Applications, Springer (2014) 399.

[20] M. Gavaises, et al., Visualisation and LES simulation of cavitation clouc formation and collapse in an axisymmetric geometry, Int. J. Multiph. Flow 68 (0) (2015) 14-26.

[21] J.-P. Franc, et al., Material and velocity effects on cavitation erosion pitting, Wear 274 (2012) 248-259.

[22] J.-P. Franc, La Cavitation: Mécanismes Physiques et Aspect Industriels, EDP Sciences, Paris, 1995.

[23] B. Belahadji, J. Franc, J. Michel, A statistical analysis of cavitation erosion pits J. Fluids Eng. 113 (4) (1991) 700-706.

24] D. Jauffres, et al., Microstructural origin of physical and mechanical properties of ultra high molecular weight polyethylene processed by high velocity compaction, Polymer 48 (21) (2007) 6374-6383.

[25] S.C. Roy, M. Fivel, J.-P. Franc, C. Pellone, Cavitation induced damage: fem inverse modelling of the flow aggressiveness, in: Proceeding of ICFD, Sendai, Japan, 2014

[26] K.-h. Nitta, A molecular theory of stress-strain relationship of spherulitic materials, Comput. Theor. Polym. Sci. 9 (1) (1999) 19-26. 